\title{
Trabecular bone strains around a dental implant and associated micromotions-A micro-CT-based three-dimensional finite element study
}

\author{
Georges Limbert ${ }^{\text {a,b,c,*}, ~ C a r l ~ v a n ~ L i e r d e ~}{ }^{\mathrm{d}}$, O. Luiza Muraru ${ }^{\mathrm{e}, \mathrm{h}}, \mathrm{X}$. Frank Walboomers ${ }^{\mathrm{f}}$, Milan Frank ${ }^{\mathrm{b}}$, \\ Stig Hansson ${ }^{\mathrm{g}}$, John Middleton ${ }^{\mathrm{a}}$, Siegfried Jaecques ${ }^{\mathrm{e}}$ \\ a Biomaterials E' Biomechanics Research Centre, School of Dentistry, Wales College of Medicine, Cardiff University, Cardiff CF14 4XY, UK \\ ${ }^{\mathrm{b}}$ FIRST Numerics Ltd., Cardiff Medicentre, Heath Park, Cardiff CF14 4UJ, UK \\ ${ }^{\mathrm{c}}$ National Centre for Advanced Tribology at Southampton (nCATS) E' Bioengineering Science Research Group, School of Engineering Sciences, University of Southampton, \\ Southampton SO17 1BJ, UK \\ d Materialise N.V., Technologielaan 15, 3001 Leuven, Belgium \\ e Division of Biomechanics and Engineering Design (BMGO), Catholic University of Leuven, Celestijnenlaan 300 C, B-3001 Leuven, Belgium \\ ${ }^{\mathrm{f}}$ Department of Periodontology E Biomaterials, Radboud University Nijmegen Medical Centre, P.O. Box 9101, THK 117 PB, 6500 HB Nijmegen, The Netherlands \\ ${ }^{g}$ Astra Tech AB Aminogatan 1, Box 14, SE-431 21 Mölndal, Sweden \\ ${ }^{\mathrm{h}}$ Multidisciplinary Research Laboratory for Biomedical and Rehabilitation Technology (MOBILAB), K.H.Kempen, Kleinhoefstraat 4, 2440 Geel, Belgium
}

\section{A R T I C L E I N F O}

\section{Article history:}

Accepted 29 January 2010

\section{Keywords:}

Dental implant

Trabecular bone

Micro-CT

Finite element

Strain

Contact

Micromotion

\begin{abstract}
A B S T R A C T
The first objective of this computational study was to assess the strain magnitude and distribution within the three-dimensional (3D) trabecular bone structure around an osseointegrated dental implant loaded axially. The second objective was to investigate the relative micromotions between the implant and the surrounding bone. The work hypothesis adopted was that these virtual measurements would be a useful indicator of bone adaptation (resorption, homeostasis, formation).

In order to reach these objectives, a $\mu$ CT-based finite element model of an oral implant implanted into a Berkshire pig mandible was developed along with a robust software methodology. The finite element mesh of the 3D trabecular bone architecture was generated from the segmentation of $\mu \mathrm{CT}$ scans. The implant was meshed independently from its CAD file obtained from the manufacturer. The meshes of the implant and the bone sample were registered together in an integrated software environment. A series of non-linear contact finite element (FE) analyses considering an axial load applied to the top of the implant in combination with three sets of mechanical properties for the trabecular bone tissue was devised. Complex strain distribution patterns are reported and discussed. It was found that considering the Young's modulus of the trabecular bone tissue to be 5, 10 and $15 \mathrm{GPa}$ resulted in maximum peri-implant bone microstrains of about 3000, 2100 and 1400. These results indicate that, for the three sets of mechanical properties considered, the magnitude of maximum strain lies within an homeostatic range known to be sufficient to maintain/form bone. The corresponding micro-motions of the implant with respect to the bone microstructure were shown to be sufficiently low to prevent fibrous tissue formation and to favour long-term osseointegration.
\end{abstract}

(c) 2010 Elsevier Ltd. All rights reserved.

\section{Introduction}

Understanding how the mechanical conditions could be controlled to optimise the speed and quality of osseointegration around immediately loaded oral implants is of paramount importance in modern dentistry (Szmukler-Moncler et al., 1998). Late failure is observed when the early osseointegrated bone is unable to maintain its mass in the long-term (Esposito

\footnotetext{
* Corresponding author at: Biomaterials \& Biomechanics Research Centre, School of Dentistry, Wales College of Medicine, Cardiff University, Cardiff CF14 4XY, UK. Fax: +442380 597051.

E-mail address: g.limbert@soton.ac.uk (G. Limbert).
}

et al., 1998). Because of the correlation between osteoblast cell lineage and strain (Jones et al., 1991), researchers have measured strain at the surfaces of (long) bones of different animal species experimentally (Goodship et al., 1979; Hylander, 1981; Lanyon et al., 1982; Lanyon and Rubin, 1984; Rubin and Lanyon, 1984). Measured peak strains ranged 2000-3000 $\mu$ strain in all of these studies and peak strains of $2200 \mu$ strain were recorded on macaque mandible during biting (Hylander, 1981). Lanyon and Rubin (1984) showed that applying a static compressive load generating a strain level of $2000 \mu$ strain was insufficient to prevent bone loss under the form of endosteal resorption and a reduction in the intracortical density. However, when the same load was applied cyclically (100 cycles per day) at a frequency of 
$1 \mathrm{~Hz}$ bone formation took place with a $24 \%$ increase in the crosssectional area. Rubin and Lanyon (1985) later replicated the experiment but by applying a bending load and discovered a linear relation between peak strain magnitude and increased cross-sectional bone area. By extrapolating the data from the experimental curve it was found that cyclic microstrain of 1000 were sufficient to maintain bone mass whilst anything above would produce bone tissue and anything below would initiate bone resorption. In another study looking at the influence of loading frequency on bone adaptation, McLeod and Rubin (1992) found that the amount of bone formation increased with the loading frequency. At $30 \mathrm{~Hz}$, a deformation of $300 \mu$ strain was sufficient to maintain bone mass while this value increased to $1200 \mu$ strain at $1 \mathrm{~Hz}$. From these experiments it is clear that strain magnitude is of particular relevance when studying bone adaptation. Osseointegrated implants have been the subject of intense research (Adell et al., 1990). It was shown by Baiamonte et al. (1996) that FE analyses can replicate in-vitro experiments with a good level of accuracy and thus are potentially useful as a pre-clinical assessment technology. FE-based studies have included axi-symmetrical, two-dimensional (2D) and 3D FE models, compare Al-Sukhun et al. (2007); Al-Sukhun et al. (2007); Baiamonte et al. (1996); Clift et al. (1992); Cruz et al. (2009); Eser et al. (2009); Geng et al. (2001); Huang et al. (2008); Huang et al. (2002); Kong et al. (2008); Kong et al. (2008); Kong et al. (2009); Lin et al. (2007); Meijer et al. (1992); Meijer et al. (1993); Merz et al. (1998); Nagasawa et al. (2008); Natali et al. (1997); Natali et al. (2006); Natali et al. (2006); Papavasiliou et al. (1997); Rieger et al. (1989); Rieger et al. (1990); Simsek et al. (2006); Sun et al. (2009); Vaillancourt et al. (1996); Van Oosterwyck (2000); Van Oosterwyck et al. (1998); van Staden et al. (2008); Wakabayashi et al. (2008); Wang et al. (2007); Williams and Williams (1997); Yang and Xiang (2007); Yu et al. (2009).

None of these studies have considered the 3D trabecular structure of the bone surrounding the implant together with their mutual sliding contact interactions and reported strains and micromotions.

The first objective of this study was to assess the strain magnitude and distribution within the 3D trabecular bone structure around an osseointegrated dental implant loaded axially. The second objective was to investigate the relative micromotions between the implant and the surrounding bone. The work hypothesis adopted was that these virtual measurements would be a useful indicator of bone adaptation (resorption, homeostasis, formation). In order to reach these objectives, a $\mu$ CT-based FE model was developed along with a robust software methodology. Given the broad range of variations for the Young's modulus of trabecular bone tissue found in the literature (Ashman and Rho, 1988; Ryan and Williams, 1986; Turner et al., 1999), a simple parametric analysis was also performed by varying the mechanical properties of bone.

\section{Materials and methods}

\subsection{Acquisition of data}

A series of $\mu$ CT scans acquisition was performed on an implanted (Berkshire) pig mandible section ( $\mu \mathrm{CT}$ machine 1072, Skyscan, Belgium) containing an osseointegrated titanium oral implant (Astra Tech AB, Mölndal, Sweden) (Fig. 1). The following $\mu$-CT scanning settings were used: $15 \times$ magnification, $1024 \times 1024$ resolution, $37 \mu \mathrm{m}$ thickness, 276 slices, $18.704 \mu \mathrm{m}$ pixel size, source: $100 \mathrm{kV} /$ $98 \mu \mathrm{A}$, exposure time: $3600 \mathrm{~ms}, 1 \mathrm{~mm}$ thick aluminium filter.

\subsection{Image segmentation and registration}

MicroCT scans were segmented in Mimics (Materialise N.V., Leuven, Belgium) and a 3D standard triangulated language (STL) surface was produced (Fig. 2) which was later topologically repaired and decimated in Materialise Magics (Fig. 2).

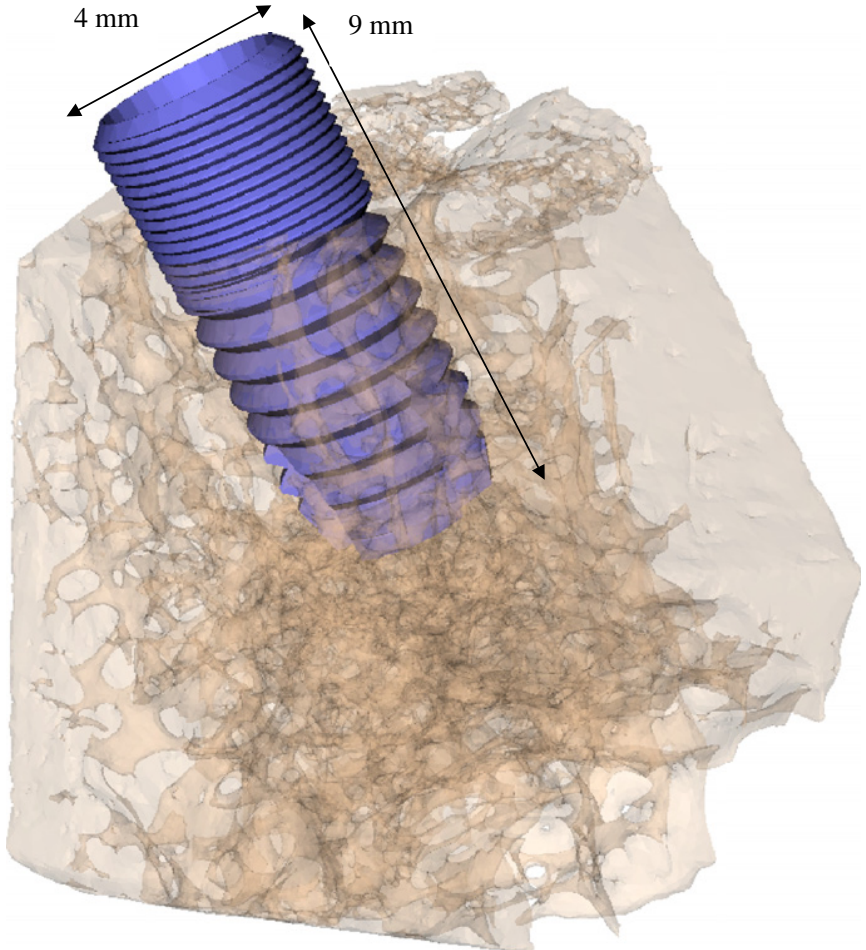

Fig. 1. Bone-implant complex after the registration procedure between the $\mu C T$ scan-based STL description of the peri-implant mandibular bone and the STL CAD model of the implant.

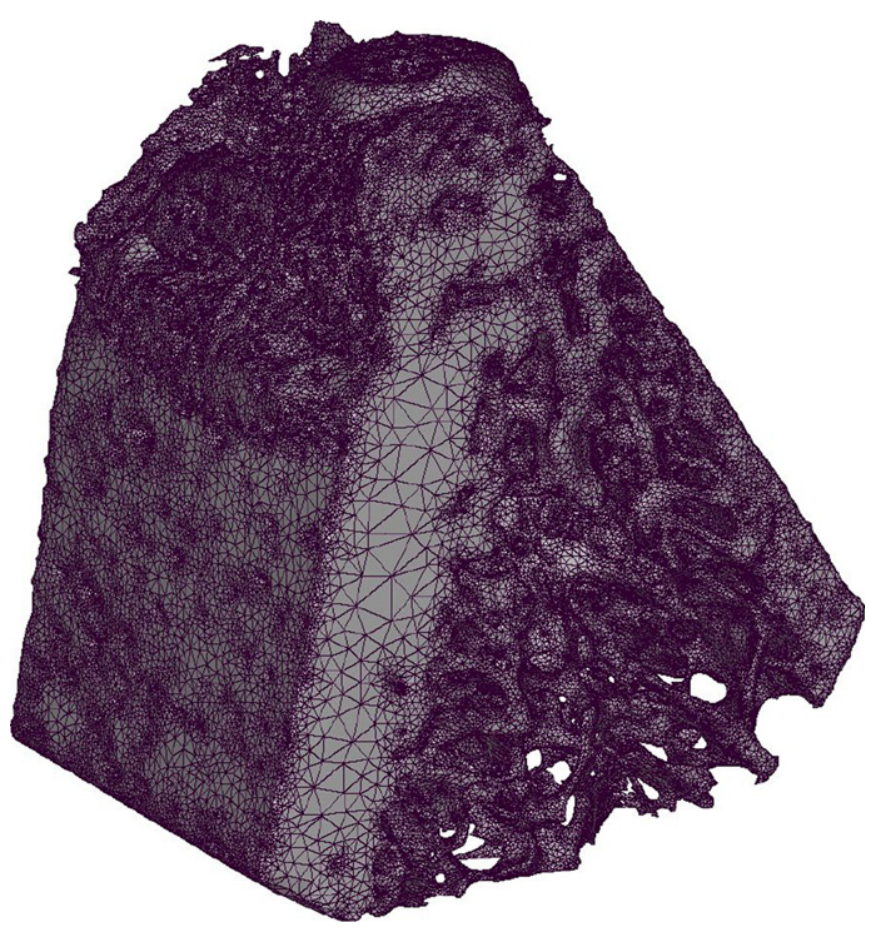

Fig. 2. 3D STL surface representation of the segmented $\mu \mathrm{CT}$ bone-implant complex after application of a decimation algorithm.

Because of the imaging artefacts caused by the presence of metal in the $\mu$ CT scanner, the implant geometry was too noisy for further accurate meshing. To overcome this limitation the idea was to mesh the CAD geometry (STEP file) of the same implant used in the experimental study independently from the trabecular structure and then register this mesh within the meshed trabecular structure (using Materialise TriMatics), perform a Boolean operation to remove what was 
the real implant with its artefacts and replace it with the independently meshed implant (Fig. 1) (Jaecques et al., 2004; Stoppie et al., 2005). It was assumed that the imaging artefacts did not affect significantly the reconstructed geometry of the trabecular structure (Jaecques et al., 2004; Jaecques et al., 2004).

\subsection{Generation of the FE model}

The STL surface of the trabecular bone structure was exported into MSC Patran (MSC Software, Palo Alto, CA, USA) and further meshed with linear tetrahedrons to limit the number of degrees-of-freedom. The STL description of the implant was meshed with linear triangular shell elements which were assumed to be rigid as the focus of the present study was on the relative strain distribution within the trabecular architecture and this was also justified by the higher stiffness of surgical titanium (115 GPa) over that of trabecular bone.

\subsection{Material properties}

There is a large variability among the different values found for the mechanical properties of trabecular bone tissue (Table 1) because of differences in experimental measurement protocols, species, age and a large number of other factors. To account for this variability, a simple parametrisation of the Young's modulus of trabecular bone $(5,10$ and $15 \mathrm{GPa})$ was performed. Because of the contact non-linearities, scaling of results was not possible. Surgical implantation causes immediate damage to the bony structure and this trauma is followed by a healing/osseointegration phase during which the mechanical properties of the tissue/structure evolve. A simplified and idealised way of accounting partly for this phenomenon is to vary the mechanical properties of trabecular tissue which is what is done in the framework of the parametric analysis.

\subsection{Interfacial properties of implant-bone interface}

The characteristics of the implant-bone interface are important (Van Oosterwyck, 2000). In the case of an isotropic Coulomb friction model (as used here) the shear stress generated between the contacting bodies is proportional to the product of the contact pressure by the coefficient of friction. If there is no friction, then there is no shear strength: the bodies are free to slide with respect to each other. If there is a non null coefficient of friction, then the shear strength is non zero and corresponds to a critical value above which sliding occurs. A $2.5 \mathrm{MPa}$ interfacial shear strength was used (Thomas and Cook, 1985). Within ABAQUS/ Standard (ABAQUS Inc., Providence, RI, USA), the behaviour of the contact interface was that of the "hard" contact pressure-overclosure model which does not allow the transmission of tensile load (ABAQUS, 2006).

\subsection{Boundary and loading conditions}

The anterior and posterior surfaces of the $\mu \mathrm{CT}$ bone block were rigidly fixed (Fig. 3). Given the scope of this study and the complex mechanical interplay that might occur at the interface between the implant and the bone and because of the complex geometry of the microarchitecture of trabecular bone, it was decided to focus on the simplest force system provided by a $100 \mathrm{~N}$ axial load.

Naturally, a dental implant is subjected to more complex force systems as measured experimentally (Duyck, 2000; Glantz et al., 1993; Merickske-Stern et al., 1992; Merickske-Stern et al., 1996).

\subsection{FE analyses}

A series of three FE analyses was devised (one for each value of the Young's modulus) and performed using ABAQUS/Standard. Non-linear contact conditions were enforced using the standard surface-based contact algorithm (ABAQUS, 2006). This algorithm uses a small-sliding penalty formulation and assumes that "the contact surfaces may undergo arbitrarily large rotations, but that a slave node will interact with the same local area of the master surface throughout the analysis". The small-sliding algorithm is enforced via the use of an internally generated contact element. Due to the impracticability of handling very large and complex meshes on 32 bit architecture processor, no mesh sensitivity analysis was performed in the present study. However, based on the authors' experience, it is believed that the mesh density chosen was sufficient to capture accurately

\section{Table 1}

Sample of values of the Young's modulus for trabecular bone found in literature.

\begin{tabular}{ll}
\hline Ryan and Williams (1986) & $0.76 \mathrm{GPa}$ \\
Ashman and Rho (1988) & $12.7 \mathrm{GPa}$ \\
Turner et al. (1999) & $17.5 \mathrm{GPa}$ \\
Turner et al. (1999) & $18.14 \mathrm{GPa}$ \\
\hline
\end{tabular}

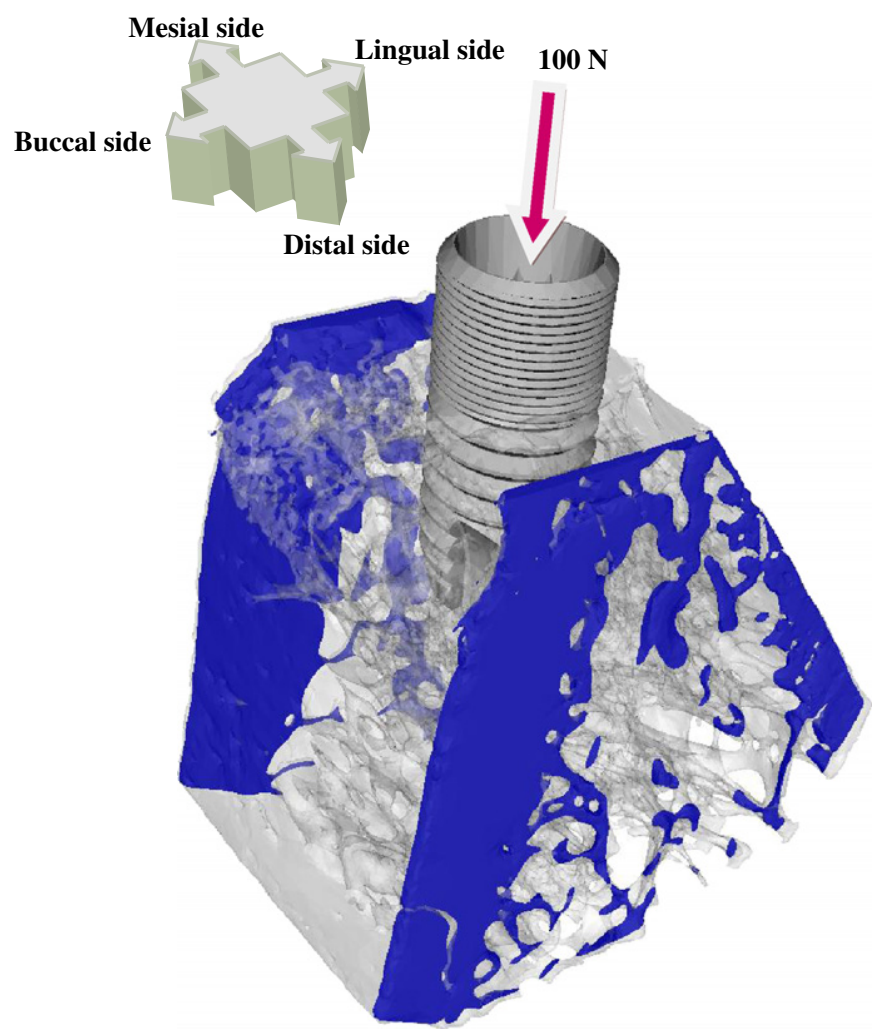

Fig. 3. Application of load to the FE model of the bone-implant complex and enforcement of boundary conditions. The axial force is represented by the red arrow whilst encastrement conditions are represented by the blue surfaces (all nodes belonging to these surfaces are rigidly fixed). The FE mesh consisted of 74,001 nodes and 739,404 elements.

strain/stress distributions. The current study considered the implant as made of a rigid material and its real intrinsic deformable mechanical behaviour would probably affect the results of the FE analyses for certain loading conditions such as bending.

\section{Results and discussion}

\subsection{Strains}

The visualisation of maximum principal strains within the bone trabeculi provides a useful insight into the complex load redistribution caused by the geometrical characteristics of the microarchitecture and that of the implant (Figs. 4-7). This is enhanced by performing virtual vertical cut along the buccolingual (Fig. 4) and mesio-distal axes (Fig. 5). The colour scale corresponds to equivalent Green-Lagrange microstrain values ( $\mu$ strain) where anything below 100 and anything above 1000 is coloured respectively in black and grey. This facilitates the identification of zones where strain magnitude is known to correspond to critical homeostatic values (Goodship et al., 1979; Hylander, 1981; Jaworski and Uhthoff, 1986; Lanyon et al., 1982; Lanyon and Rubin, 1984; Rubin and Lanyon, 1984; Rubin and Lanyon, 1985; Van Oosterwyck, 1998). Based on experimental measurements (Jaworski and Uhthoff, 1986; Rubin and Lanyon, 1985) which reported values of 50 and $10 \mu$ strain respectively a more conservative value of $100 \mu$ strain was chosen for our study. On Figs. 6 and 7, a threshold algorithm was used to remove FEs whose strain values fell below $100 \mu$ strains.

The load transmission from the implant into the bone conditions as the success or failure of a dental implant (Alexander et al., 2009; Cattaneo et al., 2007; Chou et al., 2008; Lin et al., 


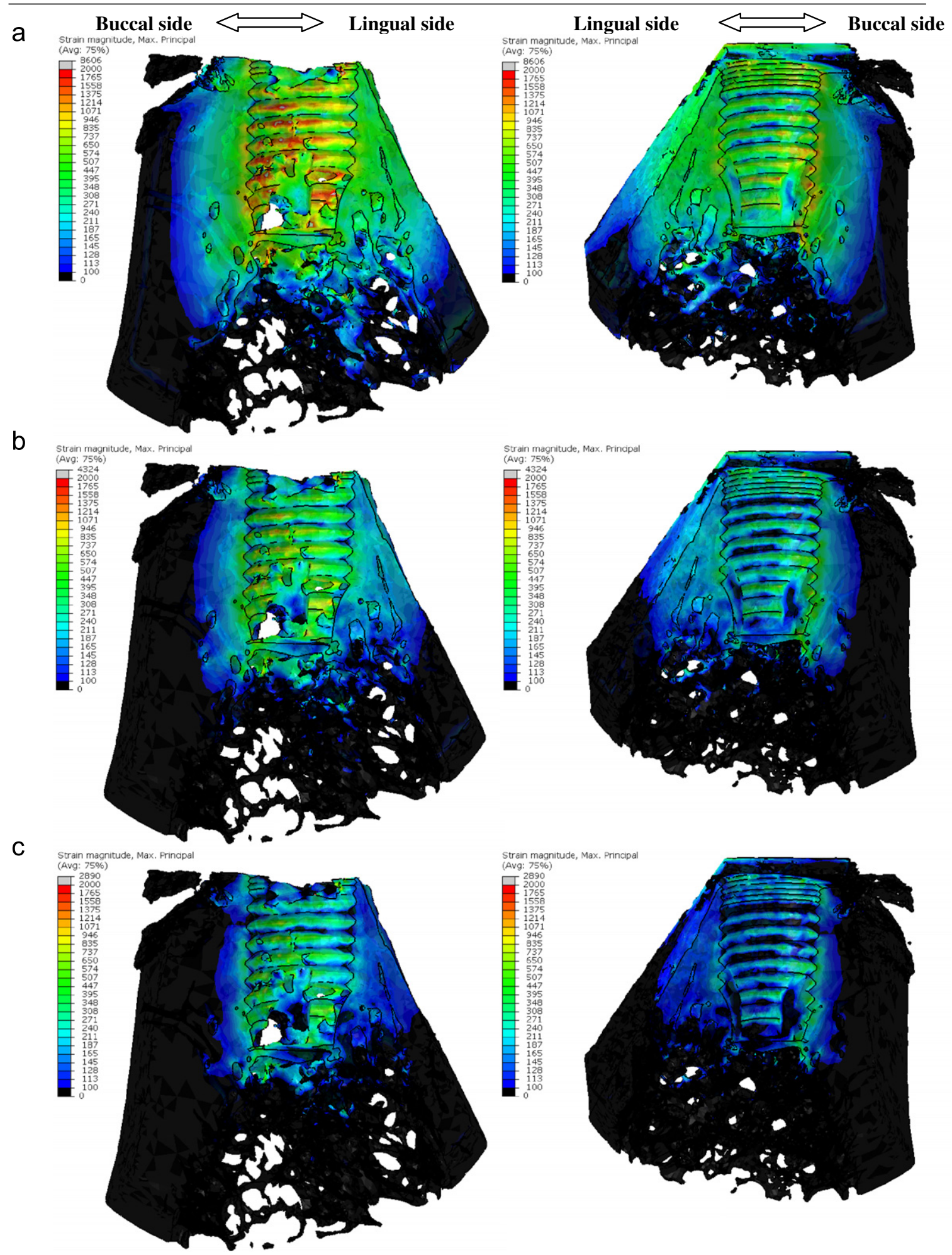

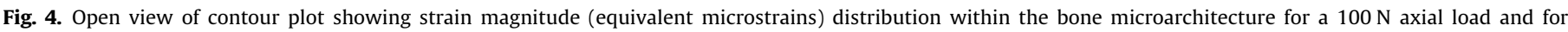

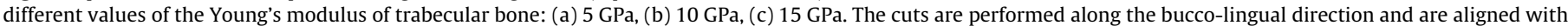
the median plane of the implant.

2008; Van Oosterwyck, 1998). Results show that strains are not distributed homogeneously within the bony structure, particularly in the peri-implant bone for both the macro- and micro-thread areas (lower strains are found in the inter-thread space). Values at this location are well above $100 \mu$ strain for a 5 GPa Young's modulus for bone whilst they fall below this threshold in parts of the peri-implant bone region for the 10 and 15 GPa bone (Figs. 4-7).

Although the implant is loaded along its long axis by a downward force, the maximum deformations of the trabecular structure are reached at the periphery of the implant above its bottom base. The cortical shell of the buccal side remains 

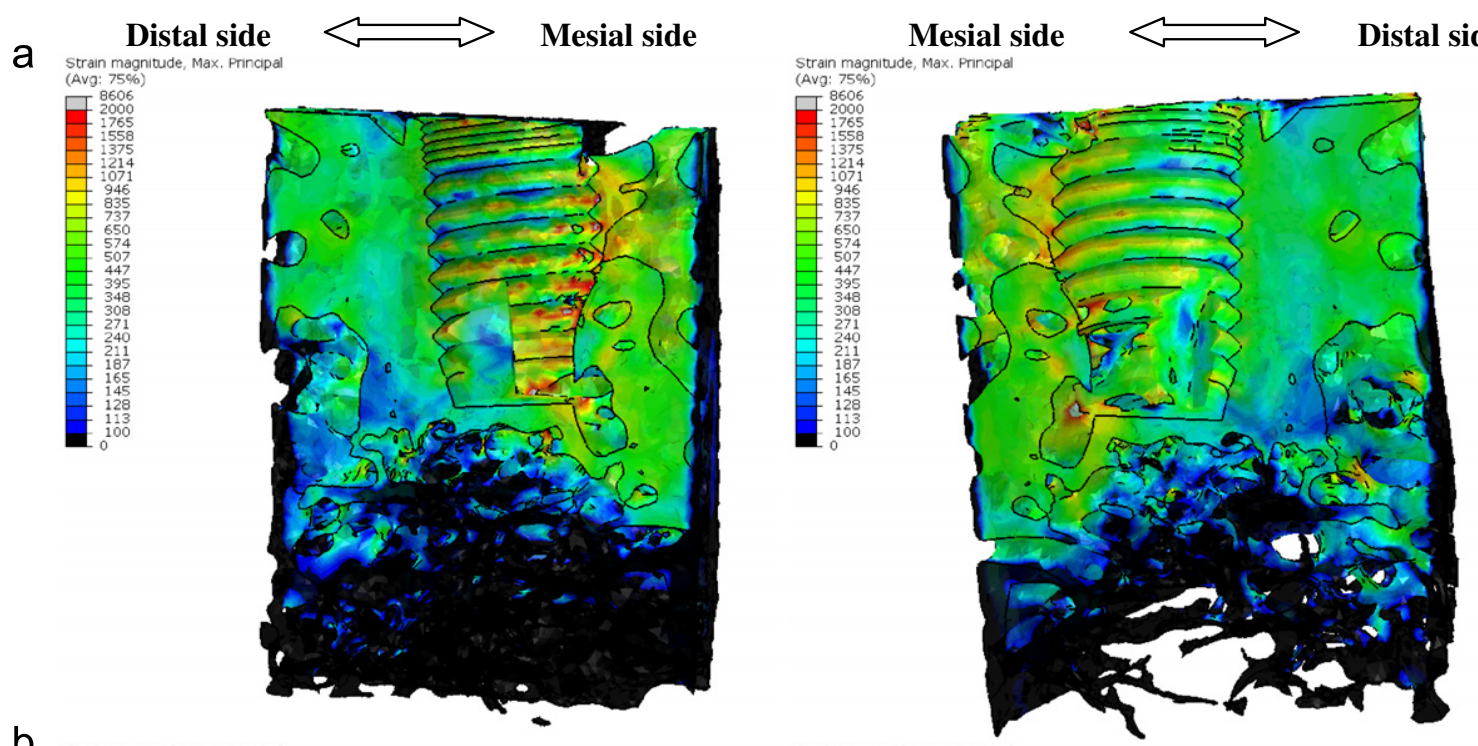

b

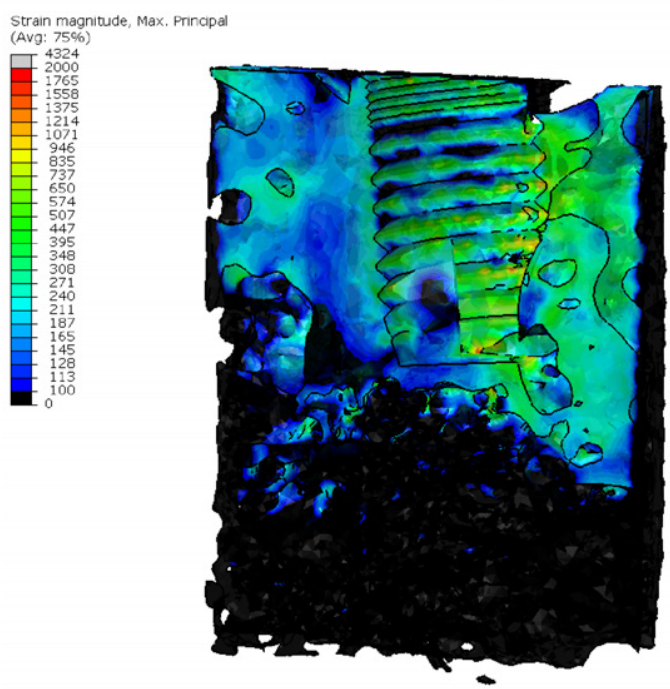

C
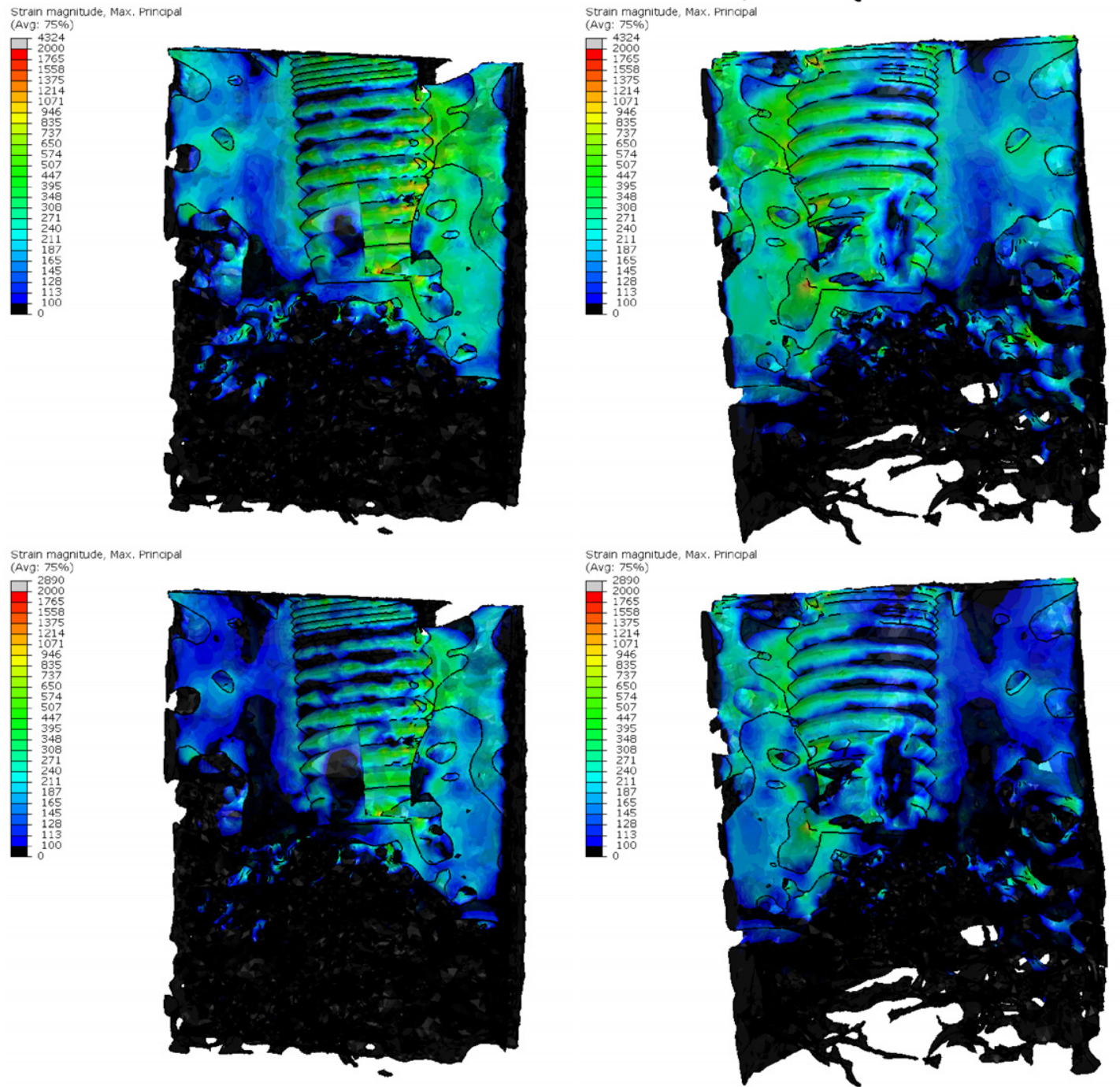

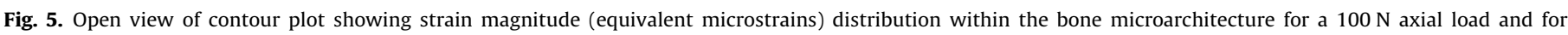

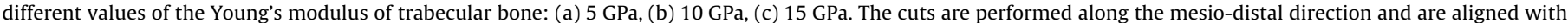
the median plane of the implant.

relatively undeformed while significant deformations happen on the cortical part of the lingual side in direct contact with the implant. The load is dissipated through the cortical shell and does not reach the lowest trabeculi. Highest peri-implant strain magnitude is found on the buccal and mesial sides of the implant (Figs. 4 and 5 respectively). It was shown experimentally by 
a

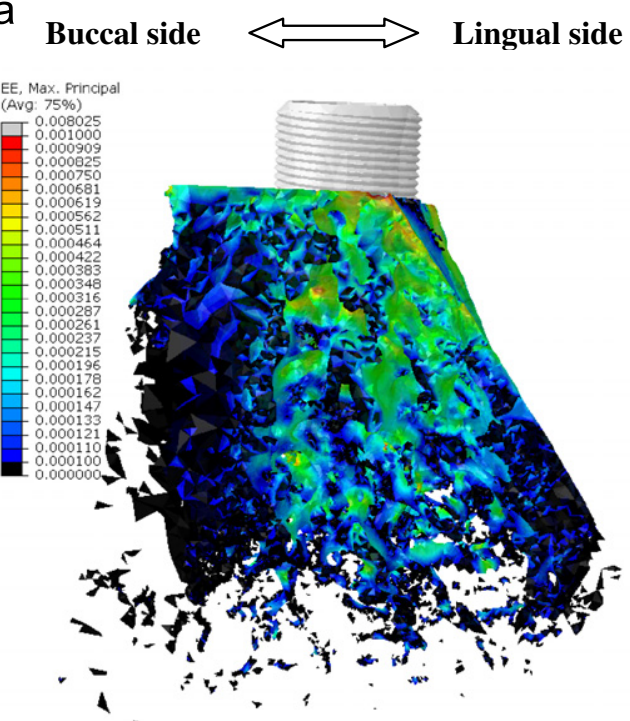

b

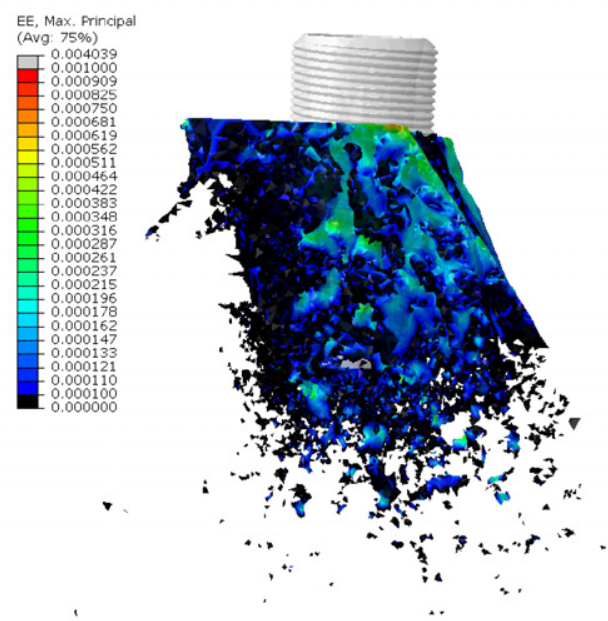

C

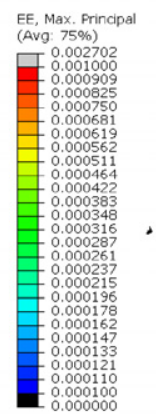

Lingual side

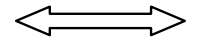

Buccal side
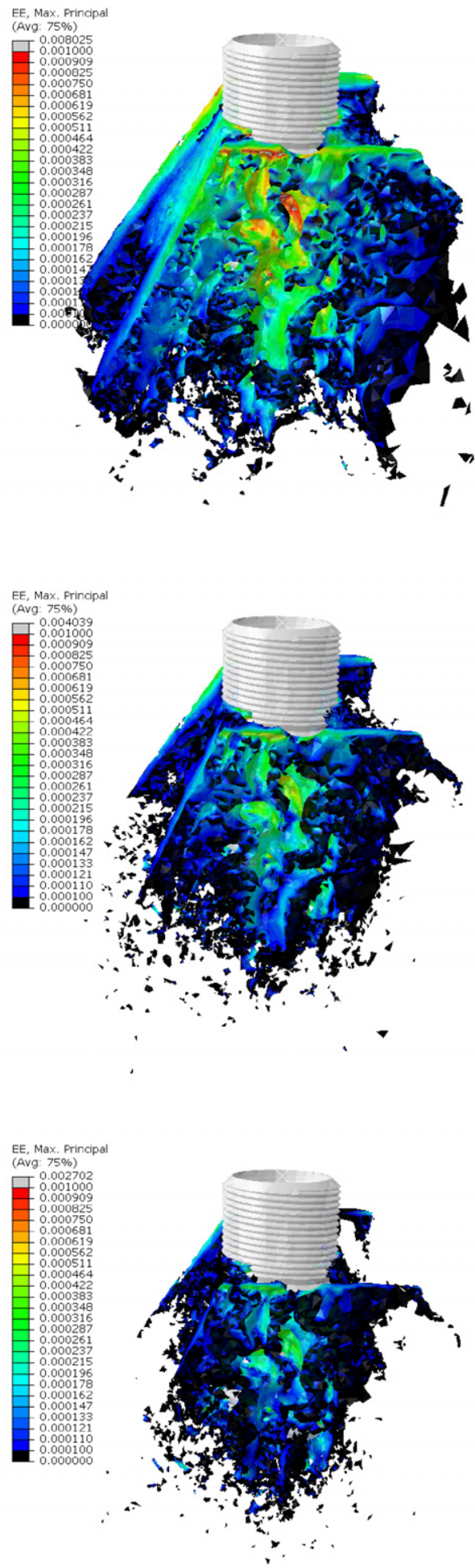

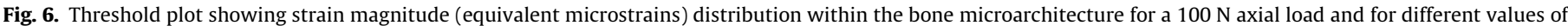
the Young's modulus of trabecular bone: (a) $5 \mathrm{GPa}$, (b) $10 \mathrm{GPa}$, (c) $15 \mathrm{GPa}$. Elements for which strain falls below 100 equivalent microstrain have been removed.

Clelland et al. (1993) by means of photoelastic strain measurements and in a recent FE study by Simsek et al. (2006) that strain levels recorded at the lingual and buccal sides of the mandible are higher than those measured at the anterior and posterior aspects. These results contrast with those of this study and can be explained by different geometries, position of the implant, loading/boundary conditions and modelling assumptions.

As expected, assigning lower mechanical properties to the trabecular bone tissue resulted in higher magnitude of strain. For the 5, 10 and $15 \mathrm{GPa}$ the extremal values of 

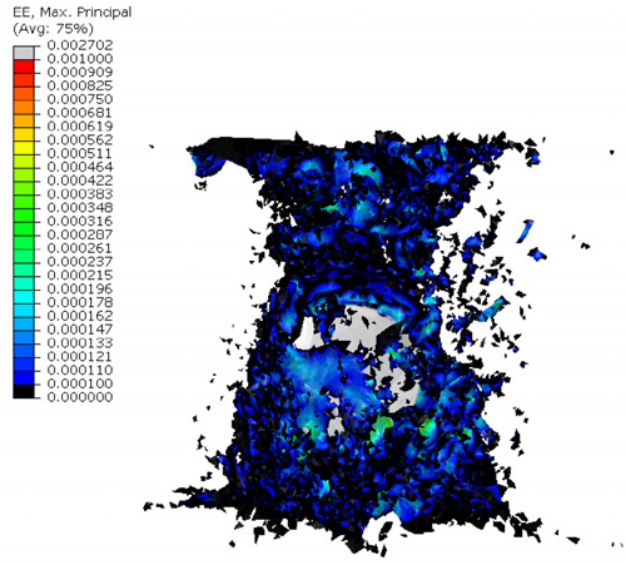

Bottom view
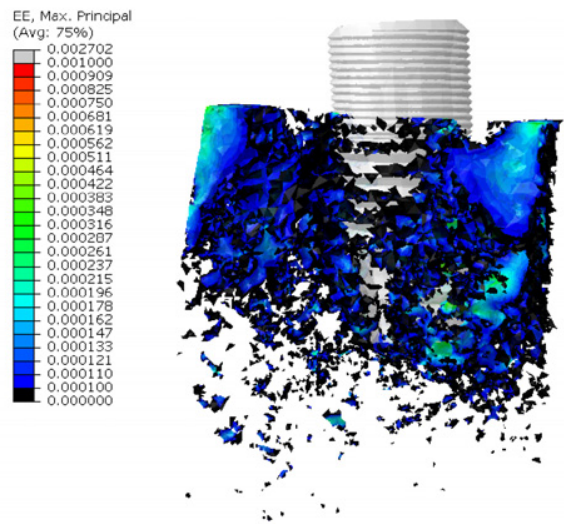

Buccal view along the disto-mesial axis
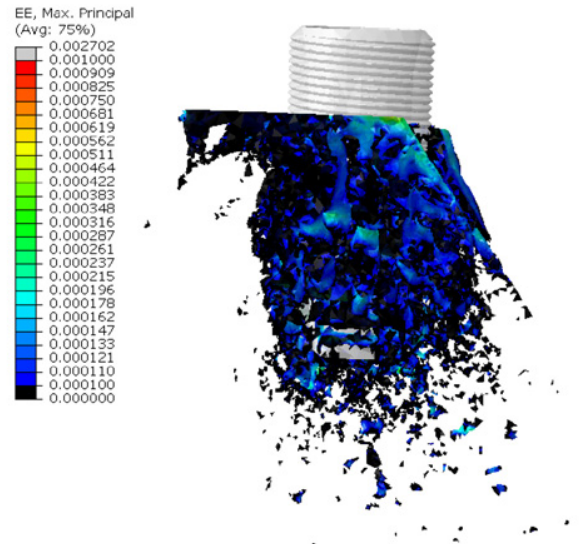

Distal view along the bucco-lingual axis

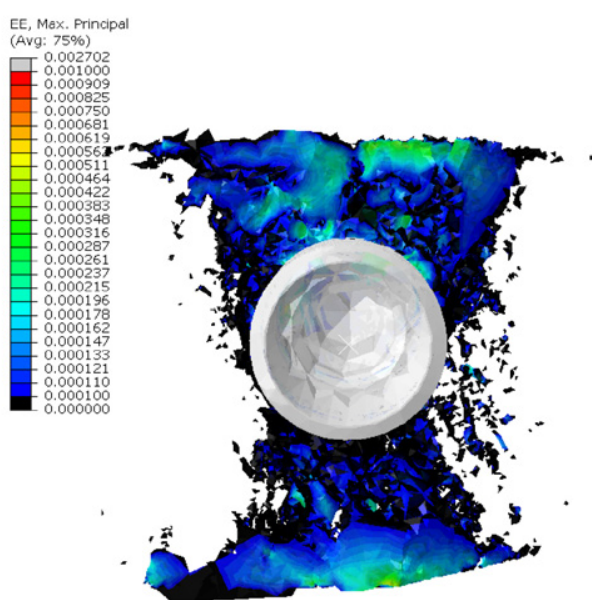

Top view
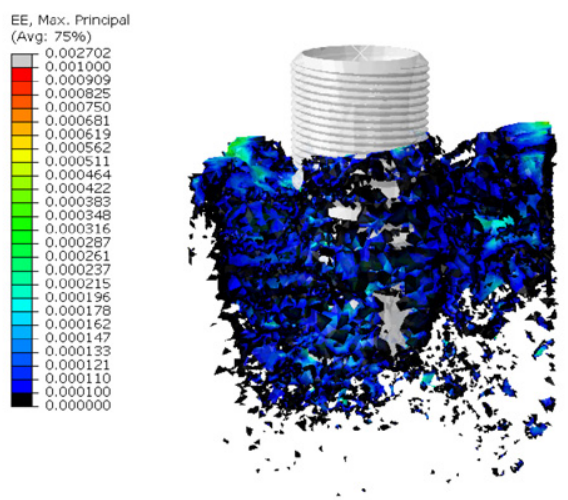

Lingual view along the mesio-distal axis

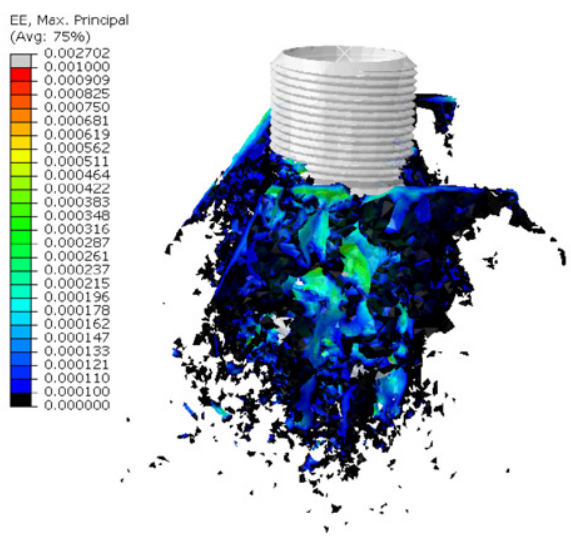

Mesial view along the bucco-lingual axis

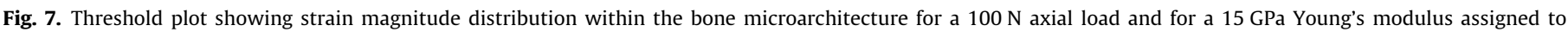
trabecular bone. Elements for which strain falls below 100 equivalent microstrain have been removed.

Table 2

External values (minimum/maximum) of principal microstrain calculated for each of the three FE analyses featuring different mechanical properties for the trabecular bone tissue.

\begin{tabular}{lrrr}
\hline Young' modulus & $5 \mathrm{GPa}$ & $10 \mathrm{GPa}$ & $15 \mathrm{GPa}$ \\
\hline Maximum principal strain & 8025 & 4039 & 2702 \\
Minimum principal strain & -8174 & -4105 & -2744 \\
\hline
\end{tabular}

maximum and minimal principal strain magnitude are listed in Table 2.

Low strain values are also found outside the direct influence zone of the implant. However, it is important to recall that the FE analyses were performed on an isolated bone sample taken away from its original mechanical and structural environment.

The embedding conditions imposed at the mesial and distal sides of the bony structure have the effect of generating higher 
than normal stresses at these particular locations and this might also affect the structural bending properties of the cortical shell structure. The strain magnitude for the models featuring a 5, 10 and 15 GPa Young's modulus (Table 2) reveals a level of strain sufficient for maintaining bone mass and initiating bone formation provided that the load would be applied cyclically (Goodship et al., 1979; Hylander, 1981; Lanyon et al., 1982; Lanyon and Rubin, 1984; Rubin and Lanyon, 1984). The deformations is of the same order of magnitude of what is measured experimentally (at the bone surfaces) on various animal species (Jaworski and Uhthoff, 1986; Rubin and Lanyon, 1985). Microstrain measurements are generally reported for cortical bone structure but, here, it is considered that the buccal and lingual sides of the bony structure are already similar to the cortical shell structure because of their intrinsic cortical-like tissue properties.

A value of $5 \mathrm{GPa}$ for the Young's modulus of the trabecular tissue is considered to be low (Goodship et al., 1979; Hylander, 1981; Lanyon et al., 1982; Lanyon and Rubin, 1984; Rubin and Lanyon, 1984) and the results of the FE analyses considering a Young's modulus of 10 and $15 \mathrm{GPa}$ are more likely to be in accordance with physiological conditions. However, the calculated values of strain might be artificially low because of the possible over-stiff behaviour of linear tetrahedrons for the particular mesh and loading conditions considered.

In stark contrast with previous studies of implant-bone interactions found in the literature (see Section 1); strains obtained from the FE analyses are given at the trabecular level which thus provides a more realistic approach than continuum models which consider the peri-implant bone as a geometrically homogeneous continuum medium. The additional advantage of modelling explicitly the trabecular micro-structure of bone instead of assuming a representative homogenised continuum volume, where one assigns anisotropic mechanical properties is that anisotropy is naturally accounted for by means of structural properties.

Most of other numerical studies found in the literature generally report stress, particularly von Mises stress, but fails to report strain magnitude and principal strain. This was addressed in the present work and the information gathered could be of particular interest for research in bone mechanobiology.

Future studies should look at the influence of contact properties and more complex boundary conditions on the load transmission from the implant to the trabecular bone structure as well as on the stress and strain distribution.

\subsection{Micromotions}

Results showed that the coefficient of friction did not have a significant effect on the magnitude of relative displacement between the implant and the bone as found by Simsek et al (2006) or on the von Mises stresses as established by Van Oosterwyck (2000). If the reference is taken as the frictionless model relative differences of $-7.1 \%$ and $+1.0 \%$ for the 0.01 and 0.1 coefficient of friction's models respectively are found (Table 3 ). When it comes to von Mises stresses the relative differences are respectively $-0.7 \%$ and $-5.4 \%$ (Table 4 ). For the absolute magnitude of displacement relative differences are respectively $-0.16 \%$ and $-1.21 \%$ (Table 5 ). The maximum relative motions between the implant and the bony structure are about half of the global micromotions of the two distinct structures. Colour plots highlighting the bone-implant relative micromotions are given for the 5 and $15 \mathrm{GPa}$ Young's modulus models on Figs. 8 and 9 respectively. The micromotion magnitude distribution is very similar between the two models. Micromotions are maximum on the sharp edges of the implant threads protruding into the bone. The maximum magnitude of micromotions is about $1.5 \mu \mathrm{m}$ for the model with a 5 GPa Young's modulus for trabecular bone for the three coefficients of friction considered $(0,0.01$ and 0.1$)$ (Table 3 ). The fact that the coefficient of friction has a negligible effect on the micromotions of the implant with respect to the bone is probably largely due to the type of load applied to the implant. i.e. axial. Also, the geometries of the implant and bone are very conforming and this offers very little scope for relative motions. This is however a desirable feature for oral implants as excessive micromovements induce fibrous tissue interposition (Brunski, 1993; Søballe et al., 1992) which are correlated with a lack of osseointegration (Adell et al., 1990; Albrektsson et al., 1981; Duyck et al., 2006; Leucht et al., 2007; Søballe et al., 1992). The acceptable threshold of micromotion not to go over was estimated by Brunski to be around $100 \mu \mathrm{m}$ (Akagawa et al., 1986; Brunski et al., 1979; Lum et al., 1991). Most of the published FE studies of dental implant assumed a state of ideal osseointegration. This idealisation amounts to a perfect bonding

Table 4

Magnitude of absolute micromotions of the trabecular bone structure (15 GPa Young's modulus) for different values of the coefficient of friction in response to a $100 \mathrm{~N}$ axial load applied to the implant.

\begin{tabular}{ll}
\hline Absolute micromotion magnitude & Maximum $(\mu \mathrm{m})$ \\
\hline Friction coefficient $=0$ & 3.526 \\
Friction coefficient $=0.01$ & 3.520 \\
Friction coefficient $=0.1$ & 3.483 \\
\hline
\end{tabular}

Table 5

Magnitude of maximum von Mises stresses of the trabecular bone structure (15 GPa Young's modulus) for different values of the coefficient of friction in response to a $100 \mathrm{~N}$ axial load applied to the implant.

\begin{tabular}{ll}
\hline Von Mises stress & Maximum (MPa) \\
\hline Friction coefficient $=0$ & 41.49 \\
Friction coefficient $=0.01$ & 41.23 \\
Friction coefficient $=0.1$ & 39.27 \\
\hline
\end{tabular}

Table 3

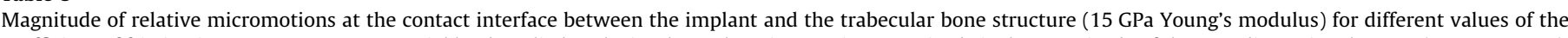

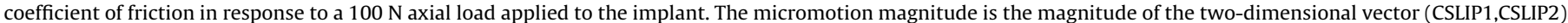
where CLSIP1 and CSLIP2 are the principal tangential director vectors coplanar with the two contacting surfaces.

\begin{tabular}{|c|c|c|c|c|c|}
\hline & CSLIP1 & CSLIP1 & CSLIP2 & CSLIP2 & Micromotion magnitude \\
\hline & Minimum $(\mu \mathrm{m})$ & Maximum $(\mu \mathrm{m})$ & Minimum $(\mu \mathrm{m})$ & Maximum $(\mu \mathrm{m})$ & Maximum $(\mu \mathrm{m})$ \\
\hline Friction coefficient $=0$ & 0.770 & 0.987 & -1.46 & 0.854 & 1.584 \\
\hline Friction coefficient $=0.01$ & 0.763 & 0.953 & -1.44 & 0.847 & 1.471 \\
\hline Friction coefficient $=0.1$ & 0.710 & 0.822 & -1.37 & 0.797 & 1.568 \\
\hline
\end{tabular}



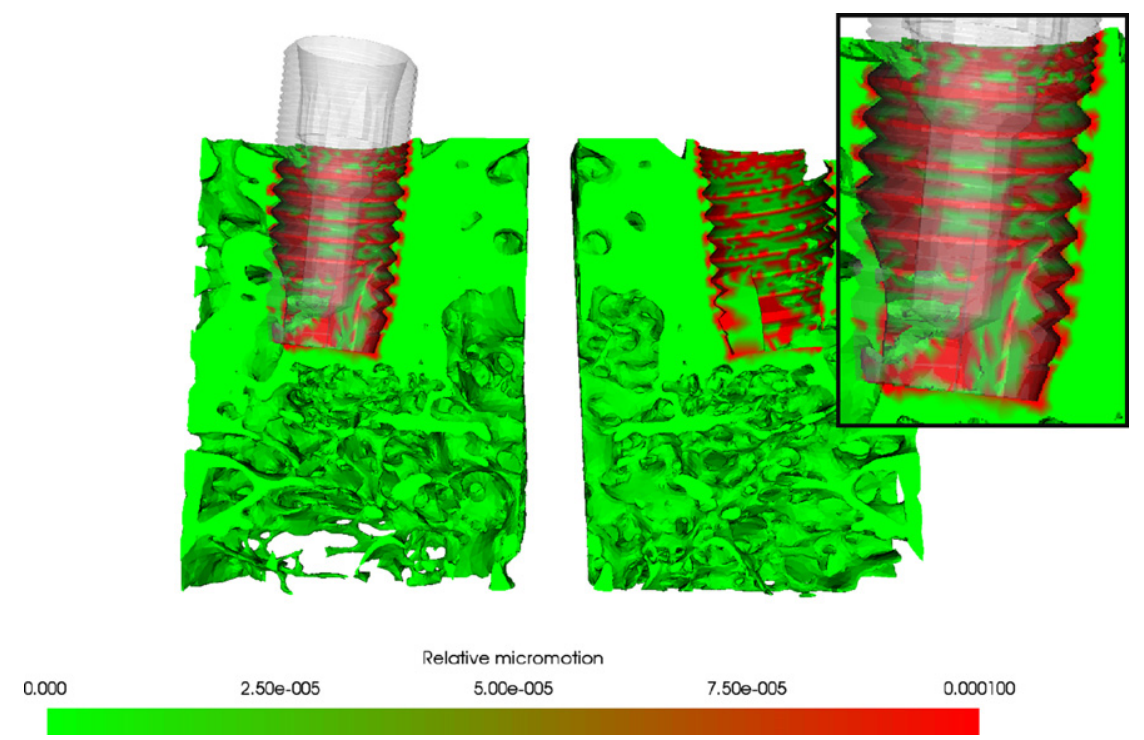

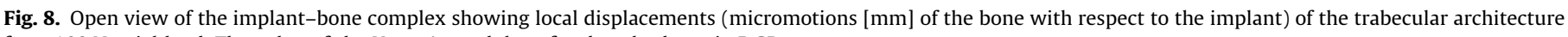
for a $100 \mathrm{~N}$ axial load. The value of the Young's modulus of trabecular bone is $5 \mathrm{GPa}$.

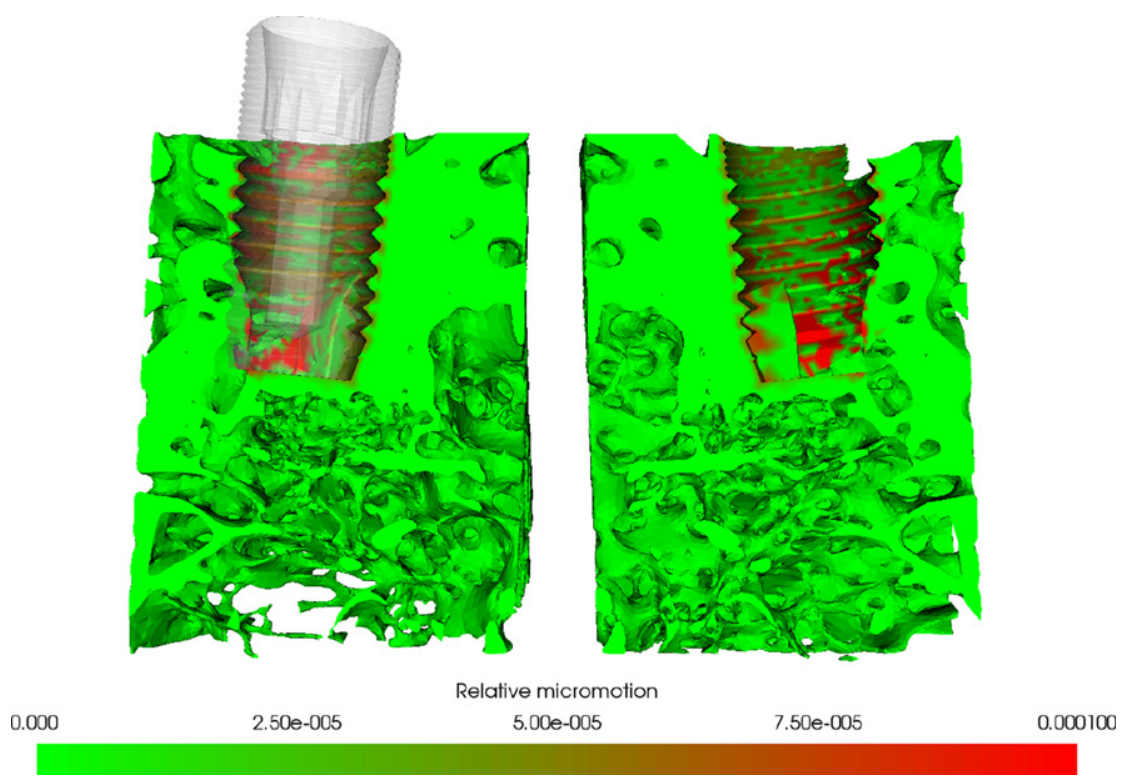

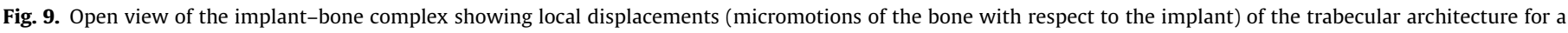
$100 \mathrm{~N}$ axial load. The value of the Young's modulus of trabecular bone is $15 \mathrm{GPa}$.

between the dental implant and the bony structure (Geng et al., 2001). The virtual representation of an osseointegrated implant corresponds to an infinite coefficient of friction between the bone and implant. Our results showed that varying the coefficient of friction between 0.01 and 0.1 had a negligible effect on the von Mises stress magnitude (Table 5). Given that the effect is also weak on micromotions (Table 3 ) one can extrapolate that increasing the coefficient of friction towards a very large value (to replicate osseointegration) would have little effect.

This corroborates a FE study by Papavasiliou et al. (1997) who showed that stress distribution and magnitude for axial and oblique loads are not affected by the level of osseointegration.

The physical implantation generates residuals stress in the bone which influences the global behaviour of the implant-bone complex. However, it is important to remind here that the implant considered in this computational study was already osseointegrated and that the residual stresses might have already affected the mechanobiological response of the tissue.

\section{Conclusion}

This study described the development of a novel $\mu$ CT-based 3D FE model of an oral implant embedded into a portion of the mandible of a pig which was used to investigate bone strains and micromotions of the implant in response to an axial load. Influence of the mechanical properties of the trabecular tissue, the coefficient of friction between trabecular bone and titanium implant on the strain distribution and micromotions were also investigated.

The major novelty of the present model is the fact that the 3D trabecular structure of the bone obtained from $\mu \mathrm{CT}$ images was accounted for together with its contact interactions with the 
dental implant. To the best of the authors' knowledge this is the first published FE model of this kind.

The new high level of resolution in the FE mesh of the trabecular bony structure provided a new insight into the complex bone strain distribution pattern and showed that the calculated level of strain and micromotions in response to a $100 \mathrm{~N}$ load is in some qualitative/quantitative agreement with published experimental data, thus confirming the usefulness/ potential of $\mu \mathrm{CT}$-based FE models in dental mechanics.

\section{Conflict of interest statement}

None

\section{Acknowledgements}

The authors would like to thank the European Union for funding part of this project [Grant QLK6-2002-02442, (IMLOAD, 2003-2006)] as well as Materialise MSC Software Benelux (particularly Dr. Marcel Edelkamp), FIRST Numerics Ltd. and Astratech for providing software applications, technical support and implant CAD data. Dr. Vasileios Bousdras and Prof. Alan Goodship from the Royal Veterinary College, University of London are gratefully acknowledged for performing implantation and providing pig tissue samples.

\section{References}

ABAQUS, 2006. ABAQUS Version 6.6, User's Manual. ABAQUS Inc., Providence, RI. Adell, R., Eriksson, B., Lekholm, U., Brånemark, P.I., Jemt, T., 1990. Long-term follow-up study of osseo-integrated implants in the treatment of totally edentulous jaws. International Journal of Oral \& Maxillofacial Implants 5, 347-359.

Akagawa, Y., Hashimoto, M., Kondo, N., Staomi, K., Tsuru, H., 1986. Initial boneimplant interfaces of submargible and supramargible endosseous singlecrystal sapphire implants. Journal of Prosthetic Dentistry 55, 96.

Al-Sukhun, J., Kelleway, J., Helenius, M., 2007. Development of a three-dimensional finite element model of a human mandible containing endosseous dental implants. I. Mathematical validation and experimental verification. Journal of Biomedical Materials Research Part A 80A, 234-246.

Al-Sukhun, J., Lindqvist, C., Helenius, M., 2007. Development of a threedimensional finite element model of a human mandible containing endosseous dental implants. II. Variables affecting the predictive behavior of a finite element model of a human mandible. Journal of Biomedical Materials Research Part A 80A, 247-256.

Albrektsson, T., Brånemark, P.I., Hansson, H.A., Lindström, J., 1981. Osseointegrated titanium implants. Requirements for ensuring a long-lasting direct bone-toimplant anchorage in man. Acta Orthopeadica Scandinavica 52, 155-170.

Alexander, H., Ricci, J.L., Hrico, G.J., 2009. Mechanical basis for bone retention around dental implants. Journal of Biomedical Materials Research Part B-Applied Biomaterials 88B, 306-311.

Ashman, R.B., Rho, J.Y., 1988. Elastic modulus of trabecular bone. Journal of Biomechanics 21, 177-181.

Baiamonte, T., Abbate, M.F., Pizzarello, F., Lozada, J., James, R., 1996. The experimental verification of the efficacy of finite element modeling to dental implant systems. Journal of Oral Implantology 22, 104-110.

Brunski, J.B., 1993. Avoid pitfalls of overloading and micromotion of intraosseous implants. Dental Implantology 4, 1-5.

Brunski, J.B., Moccia, A.F.J., Pollock, S.R., Korostoff, E., Tractenberg, D.I., 1979. The influence of functional use of endosseous dental implants on the tissue implant interface: I. histological aspects. Journal of Dental Research 58, 1953-1969.

Cattaneo, P.M., Dalstra, M., Melsen, B., 2007. Analysis of stress and strain around orthodontically loaded implants: an animal study. International Journal of Oral \& Maxillofacial Implants 22, 213-225.

Chou, H.Y., Jagodnik, J.J., Muftu, S., 2008. Predictions of bone remodeling around dental implant systems. Journal of Biomechanics 41, 1365-1373.

Clelland, N.L., Gilat, A., McGlumphy, E.A., Brantley, W.A., 1993. A photoelastic and strain gauge analysis of angled abutments for an implant system. International Journal of Oral \& Maxillofacial Implants 8, 541-548.

Clift, S.E., Fisher, J., Watson, C.J., 1992. Finite element stress and strain analysis of the bone surrounding a dental implant: effect of variations in bone modulus. Proceedings of the Institution of Mechanical Engineers Part $\mathrm{H}$-Journal of Engineering in Medicine 206, 233-241.
Cruz, M., Wassall, T., Toledo, E.M., Barra, L.P.D., Cruz, S., 2009. Finite element stress analysis of dental prostheses supported by straight and angled implants. International Journal of Oral \& Maxillofacial Implants 24, 391-403.

Duyck, J., 2000. Biomechanical Characterisation of In Vivo Load on Oral Implants Catholic University of Leuven, Leuven, Belgium.

Duyck, J., Vandamme, K., Geris, L., Van Oosterwyck, H., De Cooman, M. Vandersloten, J., Puers, R., Naert, I., 2006. The influence of micro-motion on the tissue differentiation around immediately loaded cylindrical turned titanium implants. Archives of Oral Biology 51, 1-9.

Eser, A., Akca, K., Eckert, S., Cehreli, M.C., 2009. Nonlinear finite element analysis versus ex vivo strain gauge measurements on immediately loaded implants. International Journal of Oral \& Maxillofacial Implants 24, 439-446.

Esposito, M., Hirsch, J., Lekholm, U., Thomsen, P., 1998. Biological factors contributing to failures of osseointegrated oral implants. (I) Success criteria and epidemiology. European Journal of Oral Science 106, 527-551.

Geng, J.-P., Tan, K.B.C., Liu, G.-R., 2001. Application of finite element analysis in implant dentistry: a review of the literature. The Journal of Prosthetic Dentistry 85, 585-598.

Glantz, P.O., Rangert, B., Svensson, A., Stafford, G.D., Arnvidarson, B., Randow, K. Linden, U., Hulten, J., 1993. On clinical loading of osseointegrated implants. A methodological and clinical study. Clinical Oral Implants Research 4, 99-105.

Goodship, A.E., Lanyon, L.E., McFie, H., 1979. Functional adaptation of bone to increased stress. Journal of Bone and Joint Surgery 61A, 539-546.

Huang, H.L., Hsu, J.T., Fuh, L.J., Tu, M.G., Ko, C.C., Shen, Y.W., 2008. Bone stress and interfacial sliding analysis of implant designs on an immediately loaded maxillary implant: a non-linear finite element study. Journal of Dentistry 36, 409-417.

Huang, H.M., Lee, S.Y., Yeh, C.Y., Lin, C.T., 2002. Resonance frequency assessment of dental implant stability with various bone qualities: a numerical approach. Clinical Oral Implants Research 13, 65-74.

Hylander, W.L., 1981. Patterns of stress and strain in the macaque mandible. In: Carlson, D.S. (Ed.), Craniofacial Biology. Center for Human Growth and Development, Ann Arbor, MI, USA.

IMLOAD, 2003-2006. IMLOAD Project: improving implant fixation by immediate loading.

Jaecques, S., Muraru, L., Van Lierde, C., De Smet, E., Van Oosterwyck, H., Wevers, M., Naert, I., Vander Sloten, J., 2004. In vivo micro-CT-based FE models of Guinea pigs with titanium implants: an STL-based approach. International Congress Series 1268, 579-583.

Jaecques, S., Van Oosterwyck, H., Muraru, L., Van Cleynenbreugel, T., De Smet, E. Wevers, M., Naert, I., Vander Sloten, J., 2004. Individualised, micro-CT-based finite element modelling as a tool for biomechanical analysis related to tissue engineering. Biomaterials 25, 1683-1696.

Jaworski, Z.G.F., Uhthoff, H.K., 1986. Reversibility of non traumatic disuse osteoporosis during its active phase. Bone 7, 431-439.

Jones, D.B., Nolte, H., Scholubbers, J.G., Turner, E., Veltel, D., 1991. Biochemica signal transduction of mechanical strain in osteoblast-like cells. Biomaterials $12,101-110$.

Kong, L., Hu, K.J., Li, D.H., Song, Y.L., Yang, J., Wu, Z.Y., Liu, B.L., 2008. Evaluation of the cylinder implant thread height and width: a 3-dimensional finite element analysis. International Journal of Oral \& Maxillofacial Implants 23. 65-74.

Kong, L., Sun, Y.Y., Hu, K.J., Liu, Y.P., Li, D.H., Qiu, Z.H., Liu, B.L., 2008. Selections of the cylinder implant neck taper and implant end fillet for optimal biomechanical properties: a three-dimensional finite element analysis. Journal of Biomechanics 41, 1124-1130.

Kong, L., Zhao, Y.Z., Hu, K.J., Li, D.H., Zhou, H.Z., Wu, Z.Y., Liu, B.L., 2009. Selection of the implant thread pitch for optimal biomechanical properties: a threedimensional finite element analysis. Advances in Engineering Software 40, 474-478.

Lanyon, L.E., Goodship, A.E., Pye, C.J., McFie, H., 1982. Mechanical adaptive bone remodeling. Journal of Biomechanics 15, 141-154.

Lanyon, L.E., Rubin, C.T., 1984. Static versus dynamic loads as an influence on bone remodelling. Journal of Biomechanics 17, 897-905.

Leucht, P., Kim, J.B., Wazen, R., Currey, J.A., Nanci, A., Brunski, J.B., Helms, J.A., 2007. Effect of mechanical stimuli on skeletal regeneration around implants. Bone 40, 919-930.

Lin, C.L., Chang, S.H., Chang, W.J., Kuo, Y.C., 2007. Factorial analysis of variables influencing mechanical characteristics of a single tooth implant placed in the maxilla using finite element analysis and the statistics-based Taguchi method. European Journal of Oral Sciences 115, 408-416.

Lin, C.L., Wang, J.C., Ramp, L.C., Liu, P.R., 2008. Biomechanical response of implant systems placed in the maxillary posterior region under various conditions of angulation, bone density, and loading. International Journal of Oral \& Maxillofacial Implants 23, 57-64.

Lum, L.B., Beirne, O.R., Curtis, D.A., 1991. Histological evaluation of HA-coated vs. uncoated titanium blade implants in delayed and immediately loaded applications. International Journal of Oral \& Maxillofacial Implants 6 456-462.

McLeod, K.J., Rubin, C.T., 1992. Sensitivity of the bone remodelling response to the frequency of applied strain. Transactions of the Orthopaedic Research Society, 533.

Meijer, H.J.A., Kuiper, J.H., Starmans, F.J.M., Bosman, F., 1992. Stress distribution around dental implants: influence of superstructure, length of implants, and height of mandible. The Journal of Prosthetic Dentistry 68, 96-102. 
Meijer, H.J.A., Starmans, F.J.M., Steen, W.H.A., Bosman, F., 1993. A threedimensional, finite-element analysis of bone around dental implants in an edentulous human mandible. Archives of Oral Biology 38, 491-496.

Merickske-Stern, R., Geering, A.H., Bürgin, W.B., Graf, H., 1992. Three-dimensional force measurements on mandibular implants supporting overdentures. International Journal of Oral \& Maxillofacial Surgery 7, 185-194.

Merickske-Stern, R., Piotti, M., Sirtes, G., 1996. 3D in vivo force measurements on mandibular implant supporting overdentures. Clinical Oral Implants Research 7, 387-396.

Merz, B., Mericske-Stern, R., Lengsfeld, M., Schmitt, J., Gunter, T., 1998. Finite element model of a human mandible with dental implants based on in-vivo load measuring and CT-scanning. Journal of Biomechanics 31, 42-1495.

Nagasawa, S., Hayano, K., Niino, T., Yamakura, K., Yoshida, T., Mizoguchi, T., Terashima, N., Tamura, K., Ito, M., Yagasaki, H., Kubota, O., Yoshimura, M., 2008. Nonlinear stress analysis of titanium implants by finite element method. Dental Materials Journal 27, 633-639.

Natali, A.N., Meroi, E.A., Williams, K.R., Calabrese, L., 1997. Investigation of the integration process of dental implants by means of a numerical analysis. Dental Materials 13, 325-332.

Natali, A.N., Pavan, P.G., Ruggero, A.L., 2006. Evaluation of stress induced in periimplant bone tissue by misfit in multi-implant prosthesis. The Journal of Prosthetic Dentistry 96, 338.

Natali, A.N., Pavan, P.G., Ruggero, A.L., 2006. Evaluation of stress induced in periimplant bone tissue by misfit in multi-implant prosthesis. Dental Materials 22 , 388-395.

Papavasiliou, G., Kamposiora, P., Bayne, S.C., Felton, D.A., 1997. 3D-FEA of osseointegration percentages and patterns on implant-bone interfacial stresses. Journal of Dentistry 25, 485-491.

Rieger, M.R., Fareed, K., Adams, W.K., Tanquist, R.A., 1989. Bone stress distribution for three endosseous implants. The Journal of Prosthetic Dentistry 61, 223-228.

Rieger, M.R., Mayberry, M., Brose, M.O., 1990. Finite element analysis of six endosseous implants. The Journal of Prosthetic Dentistry 63, 671-676.

Rubin, C.T., Lanyon, L.E., 1984. Regulation of bone formation by applied dynamics loads. Journal of Bone and Joint Surgery 66A, 397-402.

Rubin, C.T., Lanyon, L.E., 1985. Regulation of bone mass by mechanical strain magnitude. Calcified Tissue International 37, 411-417.

Ryan, S.D., and Williams, J.L., Tensile testing of individual bovine trabeculae. In: Proceedings of the 12th NE Bioengineering Conference, 1986, pp. 35-38.

Simsek, B., Erkmen, E., Yilmaz, D., Eser, A., 2006. Effects of different inter-implant distances on the stress distribution around endosseous implants in posterio mandible: a 3D finite element analysis. Medical Engineering \& Physics 28 199-213.

Søballe, K., Hansen, E.S., Rasmussen, H.B., Jørgensen, P.H., Bünger, C., 1992. Tissue ingrowth into titanium and hydroxyapatite-coated implants during stable and unstable mechanical conditions. Journal of Orthopaedic Research 10, 285-299.
Stoppie, N., Van der Waerden, J.P., Jansen, J.A., Duyck, J., Wevers, M., Naert, I., 2005. Validation of microfocus computed tomography in the evaluation of bone implant specimens. Clinical Implant Dentistry and Related Research 7, 87-94.

Sun, Y.Y., Kong, L., Hu, K.J., Xie, C., Zhou, H.Z., Liu, Y.P., Liu, B.L., 2009. Selection of the implant transgingival height for optimal biomechanical properties: a three-dimensional finite element analysis. British Journal of Oral \& Maxillofacial Surgery 47, 393-398.

Szmukler-Moncler, S., Salama, H., Reingewirtz, Y., Dubruille, J.H., 1998. Timing of loading and effect of micromotion on bone-dental implant interface: review of experimental literature. Journal of Biomedical Materials Research 43, 192-203.

Thomas, K.A., Cook, S.D., 1985. An evaluation of variables influencing implant fixation by direct bone apposition. Journal of Biomedical Research 19, 875-901.

Turner, C.H., Rho, J., Takano, Y., Tsui, T.Y., Pharr, G.M., 1999. The elastic properties of trabecular and cortical bone tissues are similar: results from two microscopic measurement techniques. Journal of Biomechanics 32, 437-441.

Vaillancourt, H., Pillar, R.M., McCammond, D., 1996. Factors affecting crestal bone loss with dental implants partially covered with a porous coating: a finite element analysis. International Journal of Oral \& Maxillofacial Implants 11, 351-359.

Van Oosterwyck, H., 1998. The influence of bone mechanical properties and implant fixation upon bone loading around oral implants. Clinical Oral Implants Research 9, 407-418.

Van Oosterwyck, H., 2000. Study of biomechanical determinants of bone adaptation around functionally loaded oral implants, (Ph.D. thesis), Catholic University of Leuven, Leuven, Belgium.

Van Oosterwyck, H., Duyck, J., Van der Sloten, J., Van der Perre, G., De Cooman, M. Lievens, S., 1998. The influence of bone mechanical properties and implant fixation upon bone loading around oral implants. Clinical Oral Implants Research 9, 407-418.

van Staden, R.C., Guan, H., Johnson, N.W., Loo, Y.C., Meredith, N., 2008. Step-wise analysis of the dental implant insertion process using the finite element technique. Clinical Oral Implants Research 19, 303-313.

Wakabayashi, N., Ona, M., Suzuki, T., Igarashi, Y., 2008. Nonlinear finite element analyses: advances and challenges in dental applications. Journal of Dentistry $36,463-471$.

Wang, F., Lee, H.P., Lu, C., 2007. Thermal-mechanical study of functionally graded dental implants with the finite element method. Journal of Biomedical Materials Research Part A 80A, 146-158.

Williams, K.R., Williams, A.D.C., 1997. Impulse response of a dental implant in bone by numerical analysis. Biomaterials 18, 715-719.

Yang, J., Xiang, H.J., 2007. A three-dimensional finite element study on the biomechanical behavior of an FGBM dental implant in surrounding bone. Journal of Biomechanics 40, 2377-2385.

Yu, W., Jang, Y.J., Kyung, H.M., 2009. Combined influence of implant diameter and alveolar ridge width on crestal bone stress: A quantitative approach. International Journal of Oral \& Maxillofacial Implants 24, 88-95. 